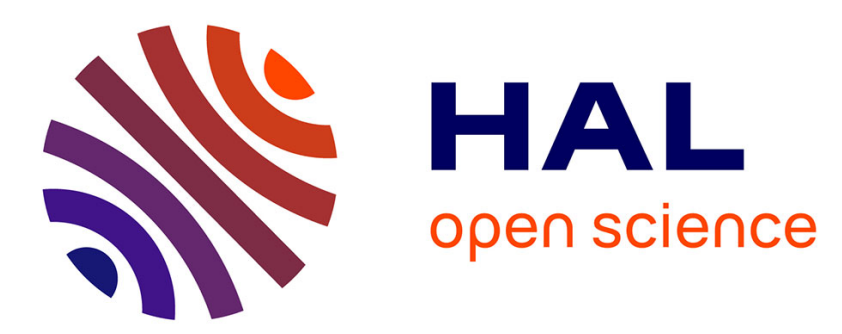

\title{
Experimental survey on the behaviour of AISI 304 steel sheets subjected to perforation
}

\author{
J. A. Rodriguez-Martinez, Alexis Rusinek, Raphaël Pesci
}

\section{To cite this version:}

J. A. Rodriguez-Martinez, Alexis Rusinek, Raphaël Pesci. Experimental survey on the behaviour of AISI 304 steel sheets subjected to perforation. Thin-Walled Structures, 2010, 48 (12), pp.966-978. 10.1016/j.tws.2010.07.005 . hal-01167261

\section{HAL Id: hal-01167261 \\ https://hal.science/hal-01167261}

Submitted on 24 Jun 2015

HAL is a multi-disciplinary open access archive for the deposit and dissemination of scientific research documents, whether they are published or not. The documents may come from teaching and research institutions in France or abroad, or from public or private research centers.
L'archive ouverte pluridisciplinaire HAL, est destinée au dépôt et à la diffusion de documents scientifiques de niveau recherche, publiés ou non, émanant des établissements d'enseignement et de recherche français ou étrangers, des laboratoires publics ou privés. 


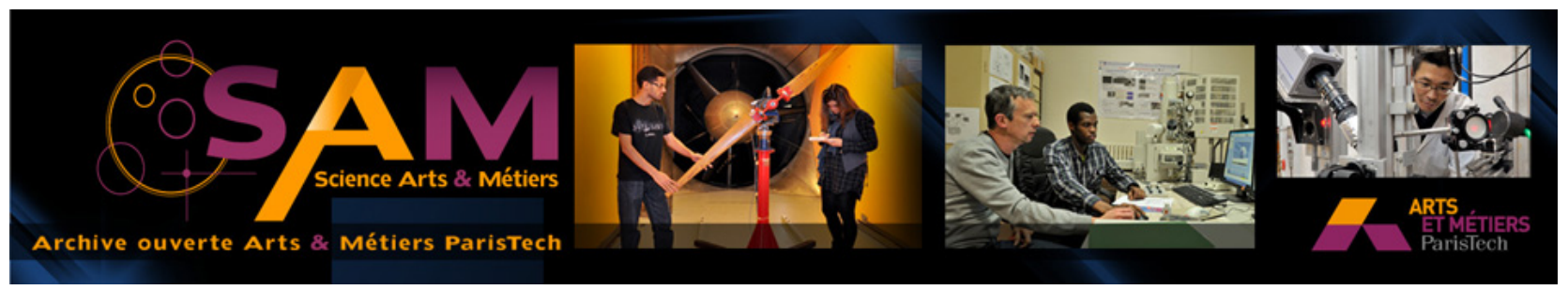

Science Arts \& Métiers (SAM)

is an open access repository that collects the work of Arts et Métiers ParisTech researchers and makes it freely available over the web where possible.

This is an author-deposited version published in: http://sam.ensam.eu

Handle ID: .http://hdl.handle.net/10985/9628

\section{To cite this version :}

J. A. RODRIGUEZ-MARTINEZ, Alexis RUSINEK, Raphaël PESCI - Experimental survey on the behaviour of AISI 304 steel sheets subjected to perforation - Thin-Walled Structures - Vol. 48, $\mathrm{n}^{\circ} 12$, p.966-978 - 2010 


\title{
Experimental survey on the behaviour of AISI 304 steel sheets subjected to perforation
}

\author{
J.A. Rodríguez-Martínez ${ }^{\mathrm{a}, *}$, A. Rusinek ${ }^{\mathrm{b}}$, R. Pesci ${ }^{\mathrm{c}}$ \\ a Department of Continuum Mechanics and Structural Analysis, University Carlos III of Madrid, Avda. de la Universidad 30, 28911 Leganés, Madrid, Spain

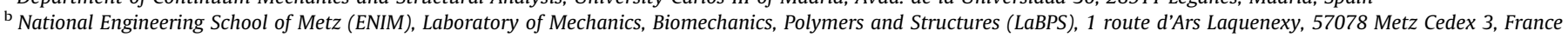 \\ ' ENSAM, Laboratory of Physics and Mechanics of Materials (LPMM), FRE CNRS 3236, 4 Rue Augustin Fresnel, 57078 Metz Cedex 3, France
}

\begin{abstract}
A B S T R A C T
This paper presents and analyzes the behaviour of AISI $\mathbf{3 0 4}$ steel sheets subjected to perforation under a wide range of impact velocities. The relevance of this steel resides in the potential transformation of austenite into martensite during mechanical loading. This process leads to an increase in strength and ductility of the material. It makes the AISI 304 attractive for many engineering applications, especially for building structural elements responsible for absorbing energy under fast loading. However, this transformation takes place only under determined loading conditions strongly dependent on initial temperature and deformation rate. In order to study the material behaviour under impact loading, perforation tests have been performed at room temperature using both, a drop weight tower and a pneumatic gas gun within the range of impact velocities $2.5 \mathrm{~m} / \mathrm{s} \leq V_{0} \leq 85 \mathrm{~m} / \mathrm{s}$. The results are compared with those reported in [18] and [21] for ES steel and TRIP 1000 steel. The comparison highlights the good performance of the AISI 304 under high loading rates. Martensitic transformation taking place in this steel during perforation is identified responsible for such behaviour.
\end{abstract}

\section{Introduction}

An exhaustive analysis of metals deformation behaviour is necessary to meet the demand of industrial sectors for materials that can bear hard mechanical loadings. For design purposes, engineering fields like aeronautical, automotive and naval industries require an accurate knowledge of the thermo-viscoplastic behaviour of metals. Particularly, high loading rate events have become increasingly important for the previously mentioned industrial sectors [1-5]. One of the main challenges of modern industry is the optimization of materials for energy absorption and crashworthiness in the design of vehicles, vessels and aircrafts [2,6-8].

For that task, new alloys with high strength, ductility and toughness have been developed. Among them, the high strength TRIP steels (Transformation Induced Plasticity) have become of great relevance [9-11]. These steels are susceptible of transforming austenite into martensite during straining. Martensitic transformation is desirable during impact loading, since it increases the strength and ductility of the material. The work hardening increase due to martensite formation delays plastic localization stabilizing material behaviour [12,13].
The controlling factor for the kinetics of martensitic transformation is the supply of free energy. The free-energy variation of the system must be large enough to enable the reaction to mount the activation barrier between austenite and martensite [14-16], Fig. 1.

In Fig. $1, M_{s}$ is the temperature at which martensite forms without an assistance of external driving force, because of the difference between the free energy of both phases, $\Delta G_{M_{s}}^{\gamma \rightarrow \alpha^{\prime}}$. Within the range $M_{s} \leq T \leq T_{0}$, a mechanical driving force $U^{\prime}$ has to be supplied to the system to induce the martensitic transformation. Transformation occurs if the mechanical driving force makes the system fulfill Eq. (1).

$\Delta G_{T}^{\gamma \rightarrow \alpha^{\prime}}+U^{\prime}=\Delta G_{M_{s}}^{\gamma \rightarrow \alpha}$

If $M_{s}^{\sigma} \leq T \leq T_{0}$, the stress required for the transformation exceeds the yield stress of the austenite and strain is required for the transformation.

At higher temperatures, $T_{0}<T<M_{d}$, the chemical driving force opposes the transformation and the mechanical work applied to the system must be greater than the difference in free energy between both phases, $U^{\prime} \geq \Delta G_{T_{0} \leq T \leq M_{d}}^{\gamma \rightarrow \alpha^{\prime}}$.

With increasing temperature, the flow stress of the austenite phase tends to decrease at any strain rate. For $T>M_{d}$, the mechanical work required for the transformation (dashed green line) cannot be achieved by straining of the austenite (solid green line). Thus, $M_{d}$ represents the temperature at which no martensitic 
transformation takes place, no matter the plastic deformation of the parent phase [17].

Due to the relation existing between deformation and temperature in the material behaviour, the strain rate also plays a crucial role in the martensitic transformation. For high strain rates, the martensitic transformation could not exist. Under dynamic loading conditions, thermal softening of the material due to adiabatic heating may prevent the phase transformation.

From previous considerations, it is clear that martensitic transformation only takes place under determined loading conditions highly dependent on the material considered. It is feasible that determined TRIP steels initially designed for absorbing energy, under crash or impact, do not show martensitic transformation at high strain rates [18]. Susceptibility of each particular material for transforming austenite to martensite under dynamic loading has to be carefully examined.

Thus, the present paper studies the impact behaviour of the TRIP steel AISI 304. This reference material, widely used in a

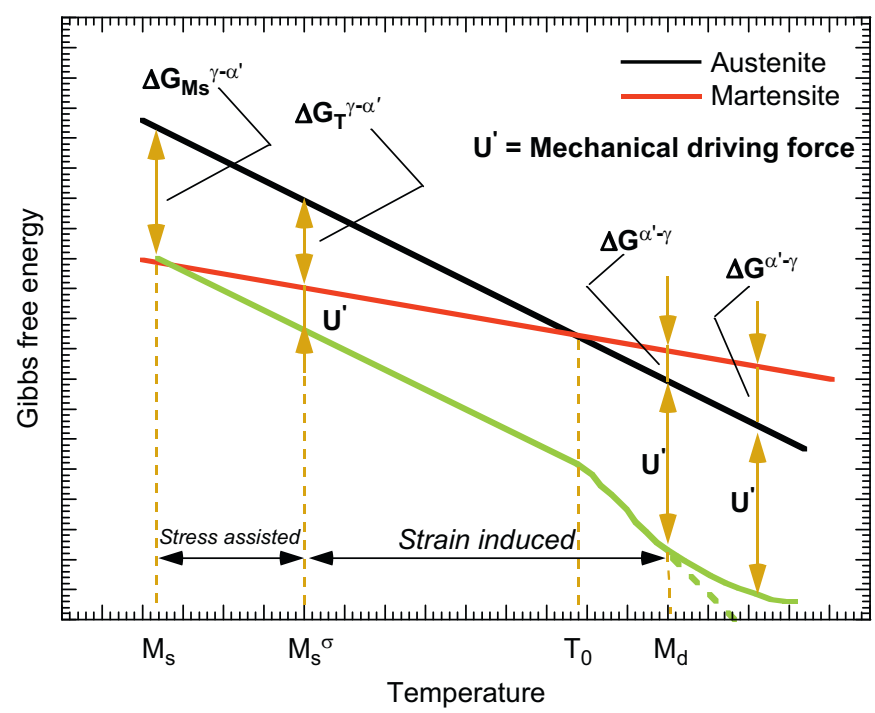

Fig. 1. Free energy of martensite and austenite as a function of temperature $[15,16]$.

Table 1

Chemical composition of the AISI 304 steel (\% weight) [22].

\begin{tabular}{llllllll}
\hline $\mathbf{C}$ & $\mathbf{M n}$ & $\mathbf{C r}$ & $\mathbf{N i}$ & $\mathbf{M o}$ & $\mathbf{C u}$ & $\mathbf{S i}$ & $\mathbf{N b}$ \\
\hline 0.06 & 1.54 & 18.47 & 8.3 & 0.30 & 0.37 & 0.48 & 0.027 \\
\hline
\end{tabular}

a

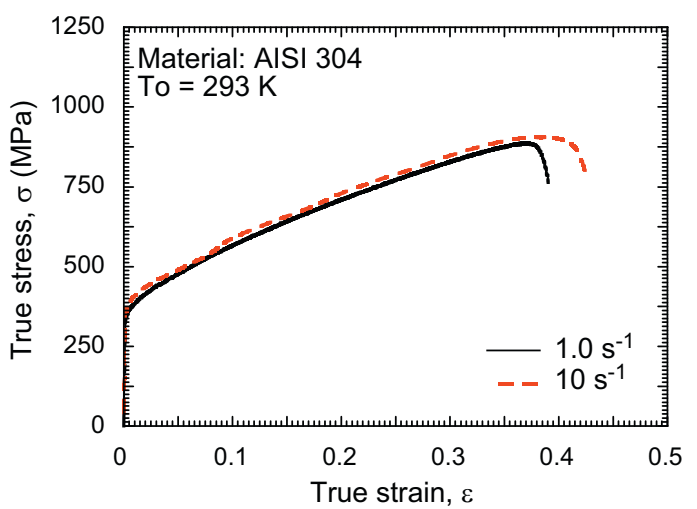

variety of industries, displays martensitic transformation at low strain rates, as demonstrated by Tomita and Iwamoto $[19,20]$. However, it is not proven that in this material the transformation may take place under impact conditions of deformation. In order to analyze such a problem, perforation tests using AISI 304 sheets have been performed at room temperature under wide ranges of impact velocities $2.5 \mathrm{~m} / \mathrm{s} \leq V_{0} \leq 85 \mathrm{~m} / \mathrm{s}$. For that task, two different experimental setups have been used, a drop weight tower and a pneumatic gas gun. Tested samples have been examined using an SEM, and a notable amount of martensite has been found in all the specimens analyzed. The martensitic transformation may be related to the excellent performance of this material under dynamic solicitation. The results from the perforation tests of the AISI 304 sheets are compared with those previously published by the authors [18,21] for other commercial steels used in the automotive industry, mild steel ES and TRIP $\mathbf{1 0 0 0}$ steel. The comparison shows the suitability of the AISI $\mathbf{3 0 4}$ for building structures responsible for absorbing energy under impact loading.

\section{AISI 304 stee}

\subsection{Microstructure and chemical composition}

The AISI 304 steel is the most versatile and most widely used stainless steel. It has an excellent forming and welding characteristics. Extensively used in a variety of industries, its typical applications include pipelines, heat exchangers railings, springs or threaded fasteners.

The AISI 304 belongs to the type called high-alloy TRIP steels. These austenitic steels (in its undeformed state, the microstructure of the AISI 304 is constituted by $100 \%$ of austenite) contain a large amount of alloying elements, such as $\mathbf{C r}$ and $\mathbf{~ N i}$, improving pitting and corrosion resistance, Table 1 .

The AISI 304 shows strain induced transformation of austenite into martensite within determined ranges of strain rate and temperature $[19,20,22,23]$. In high-alloy TRIP steels, this transformation is basically controlled by the "Magee effect" [24], as described in $[12,13,25]$.

Next, the thermo-viscoplastic behaviour of this material is examined.

\subsection{Thermo-viscoplastic behaviour}

Due to the industrial relevance of this stainless steel, several laboratories focussed their interest on the characterization of the thermo-viscoplastic behaviour of the AISI $304[23,19,20]$. In this section of the article, the experiments performed by the authors

b

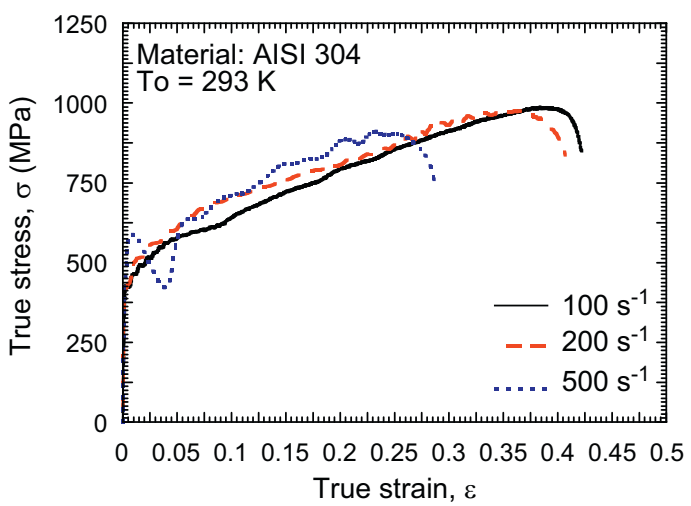

Fig. 2. True stress evolution as a function of the true strain for different strain rate levels at room temperature, steel AISI 304 [26]. 
on AISI 304 steel sheets [26] are briefly discussed. Tensile tests were conducted within wide ranges of strain rate, $10^{-4} \mathrm{~s}^{-1} \leq \dot{\bar{\varepsilon}}^{p} \leq 10^{3} \mathrm{~s}^{-1}$, at room temperature. In addition, the amount of martensite in the tested samples was determined by means of X-ray diffraction.

The macroscopic behaviour of the material is illustrated in the following graphs, Figs. 2 and 3. The material shows high strain hardening and large ductility within the whole range of strain rates considered, Fig. 2. Those characteristics are clearly noticed when the behaviour of the AISI $\mathbf{3 0 4}$ is compared with that corresponding to other commercial alloys like mild steel ES (ferritic steel) or TRIP 1000 steel (multiphase steel) [27-32], Fig. 3, frequently used in the automotive industry for building crash box structures, side panels and bumpers as reported in [33].

Using the data depicted in Fig. 3, the specific energy (energy per unit of volume) absorbed by the specimens during the tests is calculated as the area under the stress-strain curve (full integral). It is observed that, at failure, the AISI 304 steel absorbs quite larger amount of energy than the other steels involved in the comparison: $E_{\mathrm{AISI} 304}=323.68 \times 10^{6} \mathrm{~J} / \mathrm{m}^{3}>E_{\mathrm{TRIP} 1000}=172.90$ $\times 10^{6} \mathrm{~J} / \mathrm{m}^{3}>E_{\mathrm{ES}}=136.06 \times 10^{6} \mathrm{~J} / \mathrm{m}^{3}$.

Moreover in [26] was reported that straining of austenite and subsequent martensitic transformation is mainly responsible for

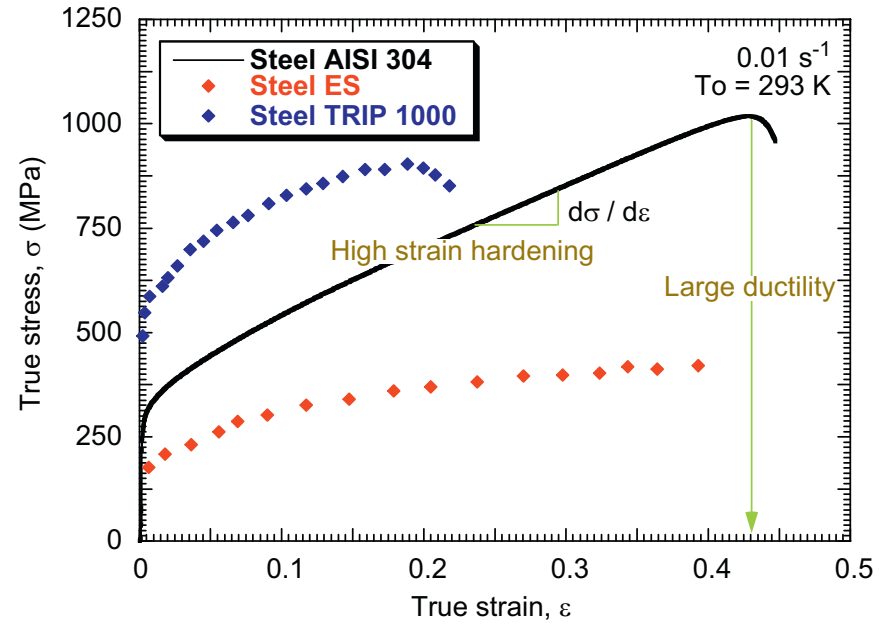

Fig. 3. True stress evolution as a function of the true strain at low strain rate and room temperature. Comparison between steel AISI 304, mild steel ES and steel TRIP $1000[26,32,34]$

a

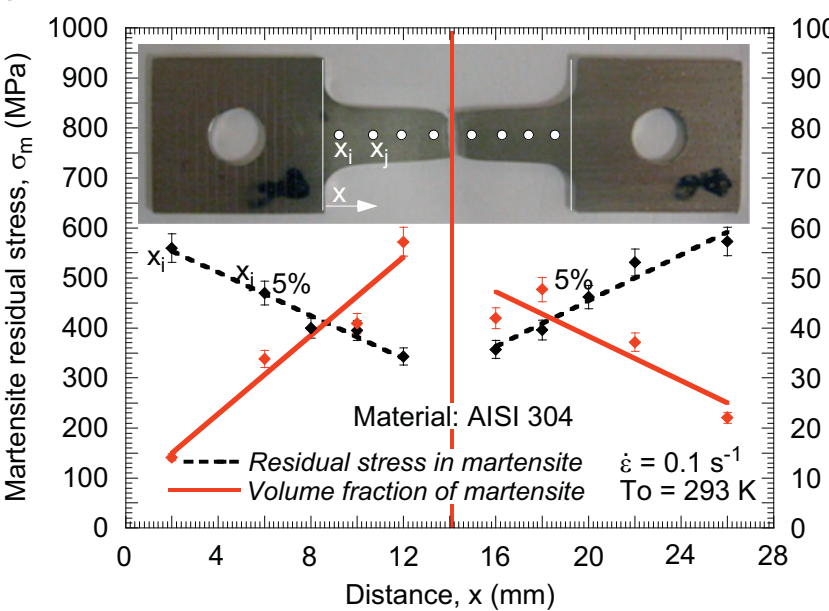

the elevated hardening rate (and therefore ductility) displayed by the AISI 304. At low strain rates $\dot{\bar{\varepsilon}}^{p}=10^{-1} s^{-1}$, in the necking zone of the tested samples (where maximum straining occurs), the volume fraction of martensite has been determined, $V_{\alpha^{\prime}} \approx 60 \%$, Fig. 4a. More remarkable is that even at higher loading rates $\dot{\bar{\varepsilon}}^{p}=10^{2} s^{-1}$, a large amount of martensite is still formed $V_{\alpha^{\prime}} \approx 35 \%$, Fig. 4b.

A dependence of the material flow stress level on the strain rate is observed, Fig. 5. However, the rate sensitivity of the AISI 304 seems to be quite independent of the plastic strain (the Volume Thermally Activated of the material is assumed independent of plastic strain), Fig. 5. Moreover it has to be noted that beyond a certain level of loading rate, the flow stress of the material sharply increases, Fig. 5. Such observation is in agreement with the experimental results reported by Follansbee [35] According to several authors [36-38], this behaviour is tied to viscous drag deformation mechanisms taking place at high strain rates [39].

Based on this knowledge of the material deformation behaviour, an analysis on the response of AISI $\mathbf{3 0 4}$ steel sheets subjected to perforation under wide ranges of impact velocities is carried out. In the following section, the experimental setups applied for conducting the perforation tests are introduced.

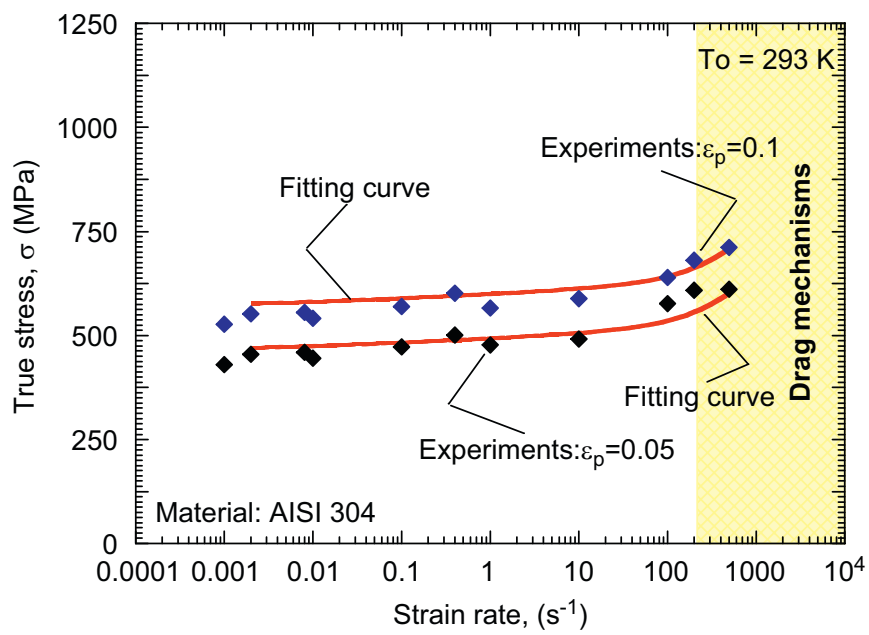

Fig. 5. True stress evolution as a function of the strain rate at room temperature for different plastic strain values, steel AISI 304.

b

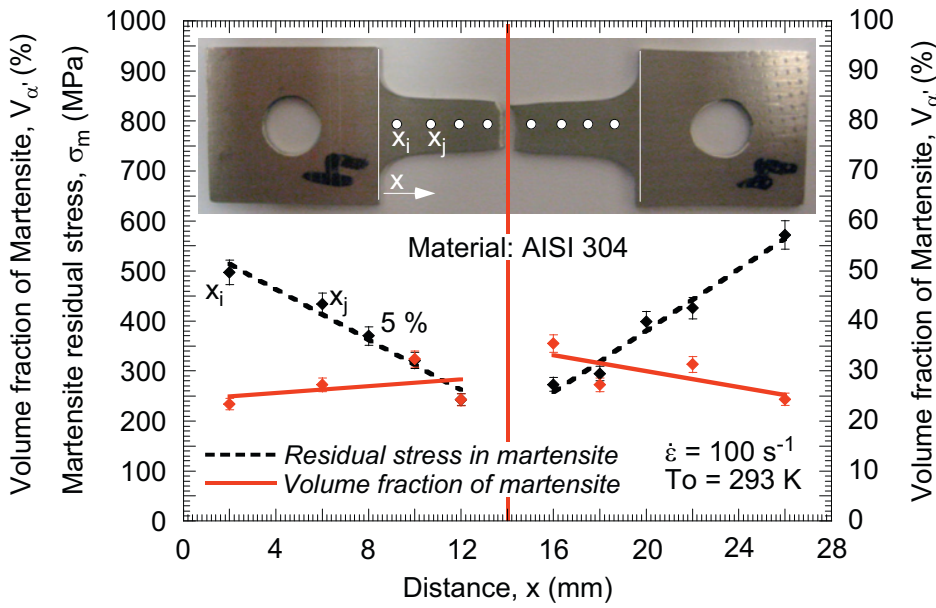

Fig. 4. Residual stress in martensite and volume fraction of martensite in tensile specimens tested at different strain rates: (a) $0.1 \mathrm{~s}^{-1}$ and (b) $100 \mathrm{~s}^{-1}$. 


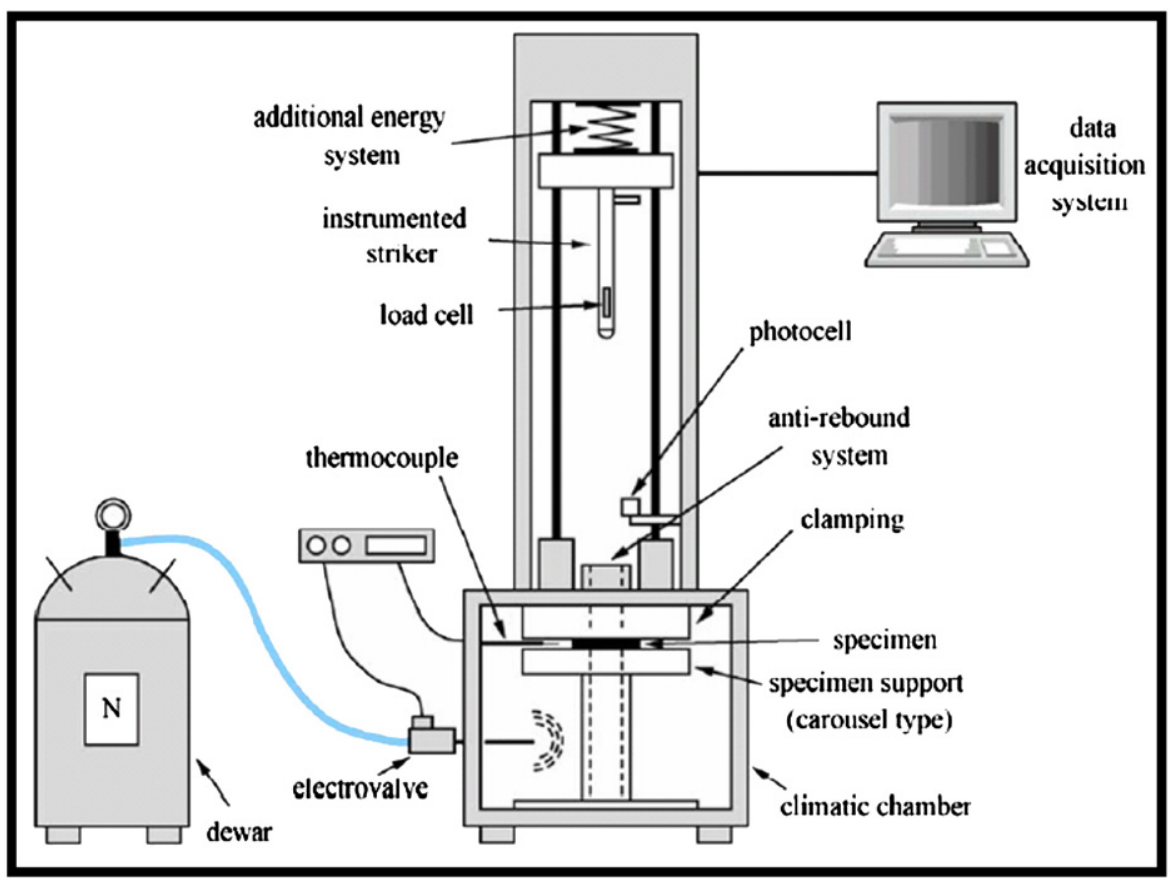

Fig. 6. Schematic representation of the drop weight tower.
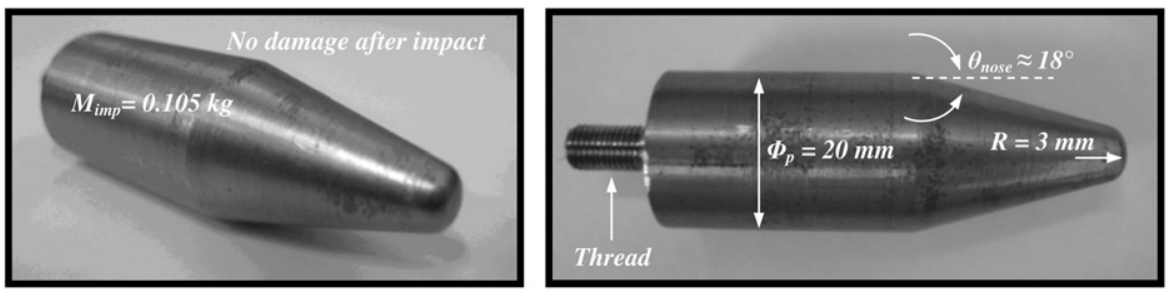

Fig. 7. Conical striker used in the drop weight tower tests.

a

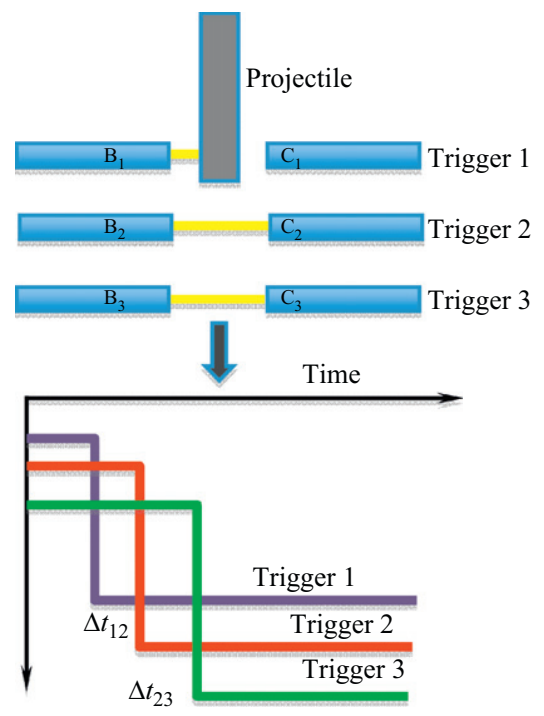

b

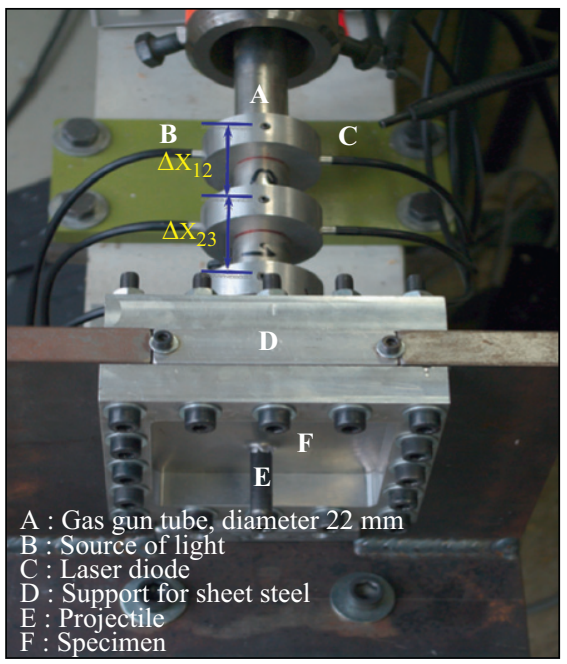

Fig. 8. (a) Scheme of the facility used for measurement of the impact velocity and (b) description of the experimental setup used in the high velocity impact tests. 


\section{Experimental setups}

\subsection{The drop weight tower}

In order to carry out the low velocity perforation tests, a drop weight tower has been used as illustrated in the schematic drawing of Fig. 6. This experimental arrangement was applied by Rodríguez-Martínez et al. [18] for low velocity perforation of

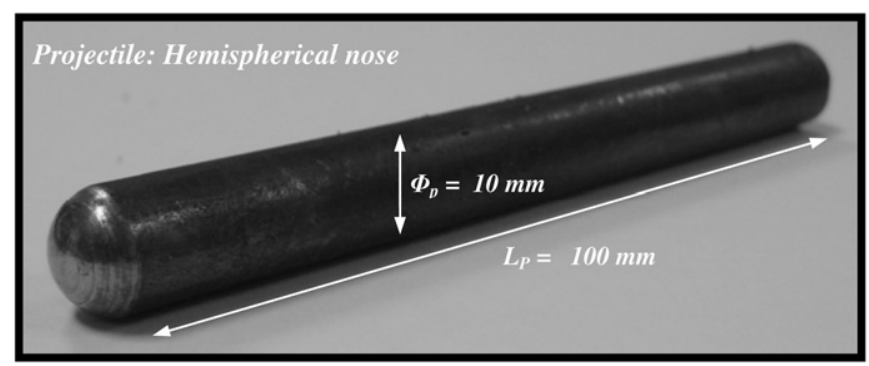

Fig. 9. Projectile used in the pneumatic gas gun tests.

a

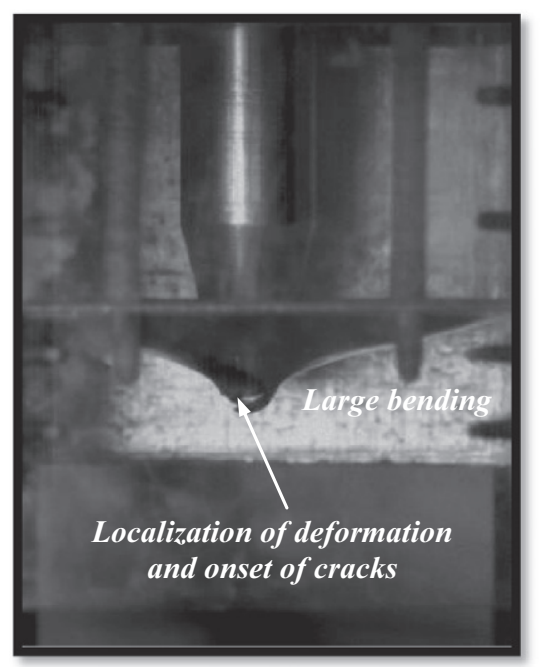

C

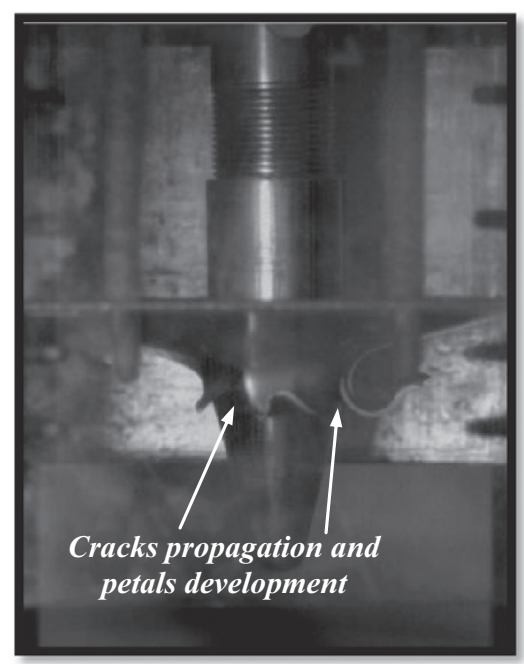

TRIP 1000 steel sheets. In this section of the manuscript, the main features of the experimental setup are provided; further details can be found in the work cited above.

This experimental configuration allows a perpendicular impact on the steel sheets, within the range of impact velocities $2.5 \mathrm{~m} / \mathrm{s} \leq V_{0} \leq 4.5 \mathrm{~m} / \mathrm{s}$. The impact velocity $V_{0}$ is fixed by the user by choosing the height from which the striker is dropped $h_{0}$, Eq. (2).

$V_{0}=\sqrt{2 g h_{0}}$

where $g$ is the gravity.

The tested square specimens were $A_{t}=100 \times 100 \mathrm{~mm}^{2}$ in size and $h=1 \mathrm{~mm}$ thick. They were clamped by screws all around the active surface, $A_{f}=80 \times 80 \mathrm{~mm}^{2}$. The screws were symmetrically fixed in order to avoid any disturbances during the test. The device used to clamp the steel sheets had a transparent side made of PMMA. Such an arrangement allowed to film the perforation process by means of a high speed camera.

The steel striker used has a conical shape, as shown in Fig. 7. Its larger diameter is $\Phi_{p}=20 \mathrm{~mm}$ and its mass is $M_{\mathrm{imp}}=0.105 \mathrm{~kg}$. After machining the striker has been oil quenched to avoid its damage or erosion during perforation, Fig. 7.

b

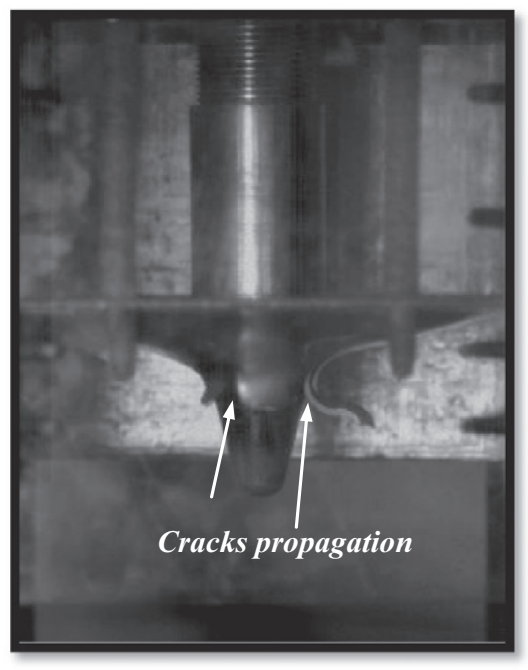

d

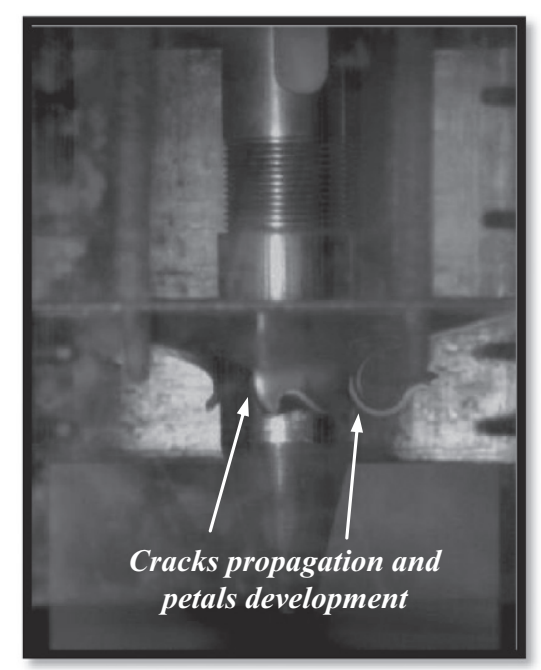

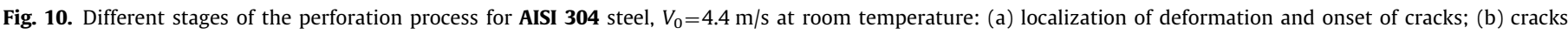

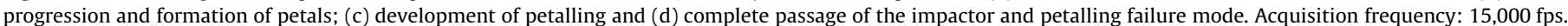
Picture resolution: $640 \times 480$ pixels. 
Detail: Target pierced

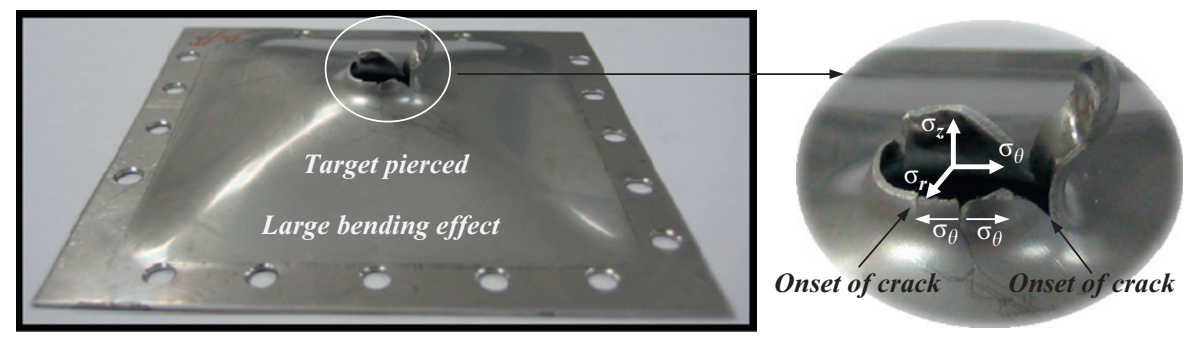

Fig. 11. Target pierced for $V_{0}=3.25 \mathrm{~m} / \mathrm{s}$ at room temperature, AISI 304 steel.

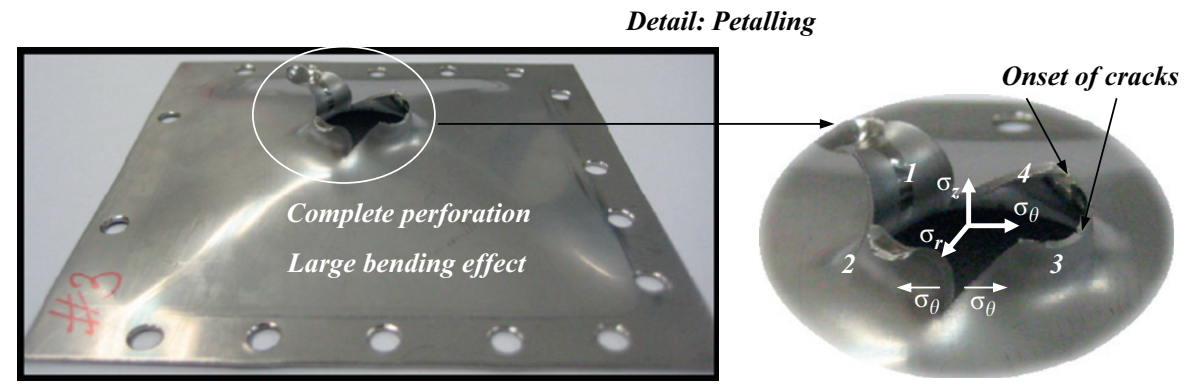

Fig. 12. Petalling failure mode for $V_{0}=3.5 \mathrm{~m} / \mathrm{s}$ at room temperature, AISI $\mathbf{3 0 4}$ steel.

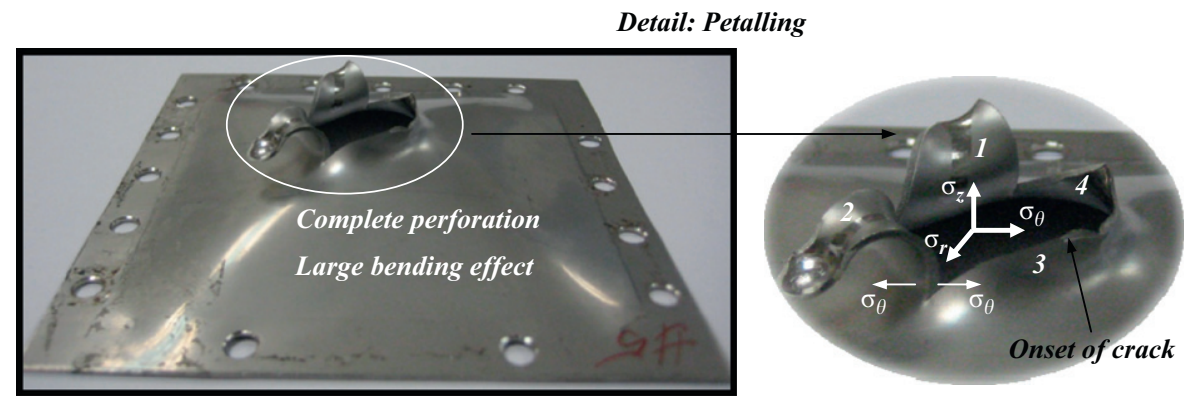

Fig. 13. Petalling failure mode for $V_{0}=4.4 \mathrm{~m} / \mathrm{s}$ at room temperature, AISI 304 steel.

The striker was attached to the instrumented bar of the drop weight tower, whose mass is $M_{\mathrm{bar}}=0.761 \mathrm{~kg}$. Additional mass was added to the setup in order to increase the effective mass to $M_{\text {total }}=18.787 \mathrm{~kg}$ (the range of the impact energy covers 59 $J \leq E_{i} \leq 190 \mathrm{~J}$ ). A load cell placed on the striker enabled to record the impact force versus time signal. The force cell records 4000 measurements, which are equally spaced within the acquisition time. For all the tests conducted, the acquisition time was set to $16 \mathrm{~ms}$ leading to an acquisition frequency of $250 \mathrm{kHz}$. This high acquisition frequency allows for an accurate definition of the force evolution as a function of time. The time dependent velocity $V(t)$ and displacement of the striker during perforation $\delta_{s}(t)$ can be calculated by an integration of the impact force versus time curve $F(t)$, Eqs. (3)-(5).

$$
\begin{aligned}
& F(t)=M_{\text {total }}(a(t)+g) ; \quad a(t)=\frac{F(t)-M_{\text {total }} g}{M_{\text {total }}} \\
& V(t)=V_{0}-\int_{0}^{t} \frac{F(t)-M_{\text {total }} g}{M_{\text {total }}} d t
\end{aligned}
$$

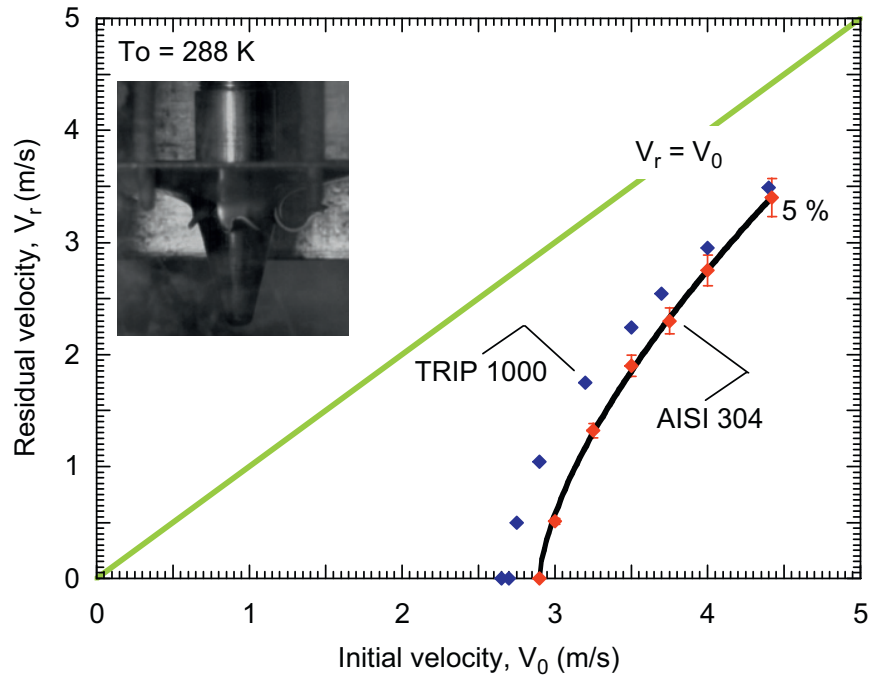

Fig. 14. Residual velocity versus impact velocity. Comparison between AISI 304 and TRIP 1000 steels. 
$\delta_{s}(t)=\int_{0}^{t}\left[V_{0}-\int_{0}^{t} \frac{F(t)-M_{\text {total }} g}{M_{\text {total }}} d t\right] d t$

where $a(t)$ is the deceleration of the striker during perforation.

\subsection{The pneumatic gun}

In order to conduct the high velocity perforation tests, a pneumatic gas gun has been used as illustrated in Fig. 8. This

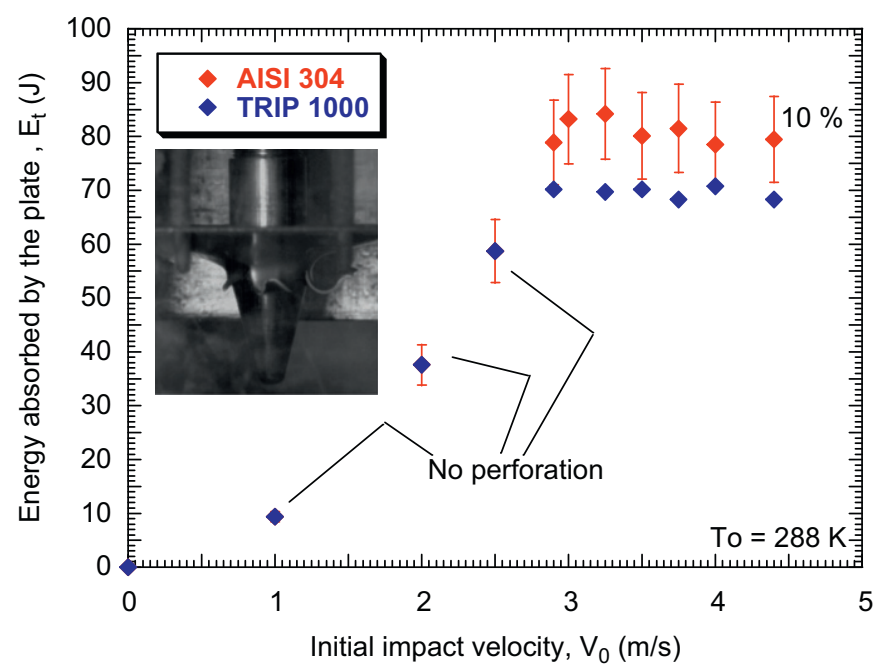

Fig. 15. Energy absorbed by the target as a function of the impact velocity. Comparison between AISI 304 and TRIP 1000 steels.

a

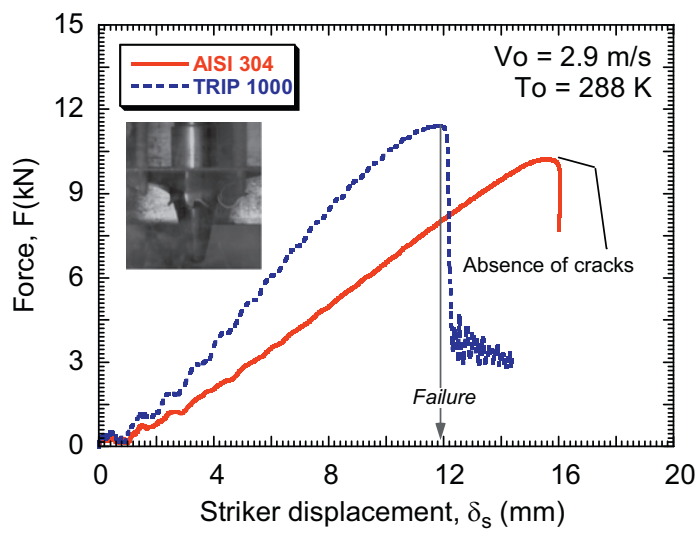

C

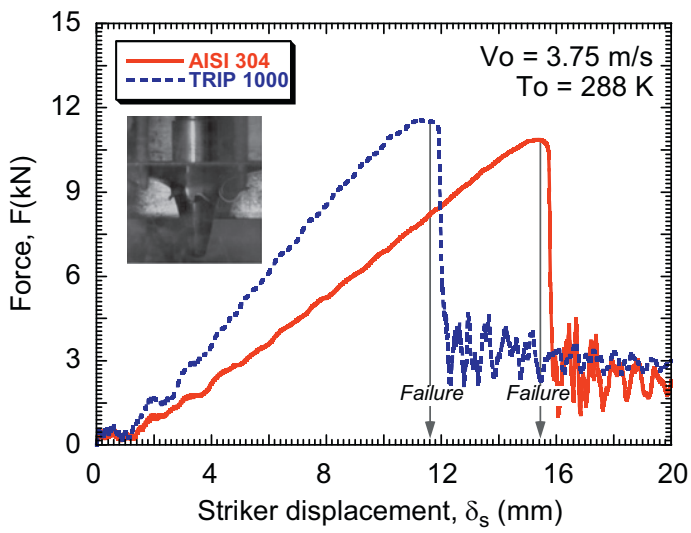

experimental arrangement was applied by Rodríguez-Martínez et al. [21] for perforation of ES steel sheets. In this section of the manuscript, the main features of the experimental setup are given; details can be found in the work cited above.

This experimental configuration allows a perpendicular impact on the steel sheets within the range of impact velocities $25 \mathrm{~m} / \mathrm{s} \leq V_{0} \leq 100 \mathrm{~m} / \mathrm{s}$. To measure the impact velocity, 3 sources of light $B_{i}$ coupled to 3 laser diodes $C_{i}$ and 3 time counters are used. When the projectile passes through a source of light, Fig. 8a, a time counter is trigged. This procedure is repeated 3 times defining two time intervals $\Delta t_{12}$ and $\Delta t_{23}$, Fig. 8a. Knowing the distance between the 3 sources of light is possible to measure two instantaneous projectile-velocities $V_{0}^{i j}$. Their average $\bar{V}_{0}$ was used to define the impact velocity values reported throughout this article.

The samples are $A_{t}=140 \times 140 \mathrm{~mm}^{2}$ in size and $h=1 \mathrm{~mm}$ thick. The active part of the specimen, after it is screwed and clamped on the support, is $A_{f}=100 \times 100 \mathrm{~mm}^{2}$. The mass of the hemispherical projectile used is $M_{p}=0.063 \mathrm{~kg}$ and its dimensions are shown in Fig. 9.

The projectiles were made of Maragin steel, which exhibits very high yield stress. In addition, the projectiles underwent a heat treatment in order to increase their hardness. It permitted to avoid their damage or erosion during perforation.

Next the perforation tests performed using both experimental techniques are analyzed.

\section{Impact behaviour of AISI 304 steel sheets}

First of all, the low velocity perforation experiments conducted using the drop weight tower setup are examined.

b

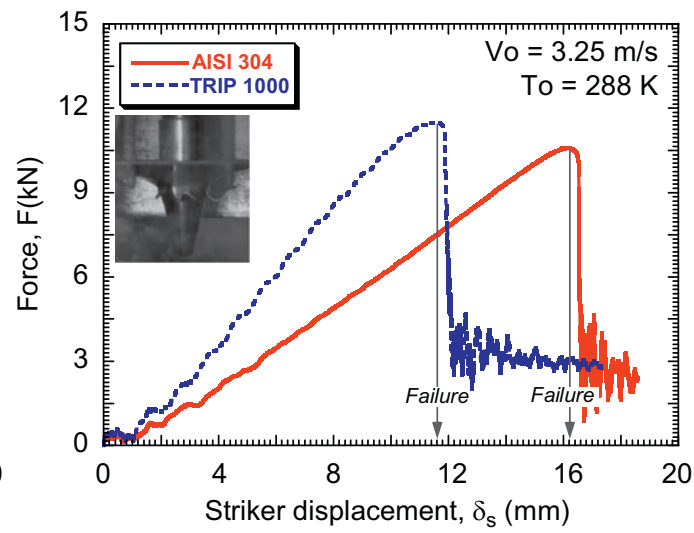

d

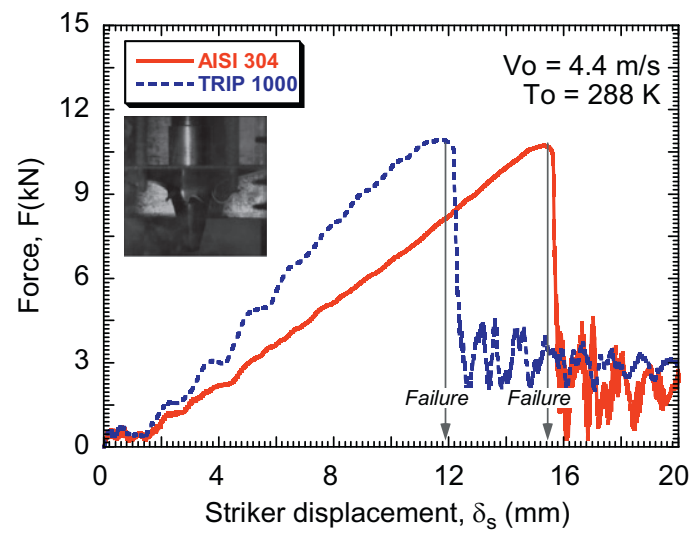

Fig. 16. Force evolution as a function of the striker displacement for different impact velocities. Comparison between AISI $\mathbf{3 0 4}$ and TRIP $\mathbf{1 0 0 0}$ steels. 


\subsection{The low velocity impact tests}

In this section of the paper, the results obtained for the AISI 304 are compared with those reported by Rodríguez-Martínez et al. [18] for the perforation of TRIP 1000 steel sheets (both AISI 304 and TRIP 1000 steels samples have the same size and thickness). Differences in the response under loading of both materials are discussed.

The first step is to examine the perforation mechanisms via the video images recorded during the tests, Fig. 10.

The perforation process can be split up into several stages. At the beginning of the loading process, the deformation is localized in the small area corresponding to the interface striker/plate, as shown in Fig. 10a. During the process of localization, the target is strongly bent until the onset of cracks occurs, Fig. 10b. Then, the cracks start to propagate radially enhanced by the increasing circumferential strain caused by the passage of the projectile, Fig. 10c. Crack propagation is precursor to petals formation, Fig. 10c. Finally, the cracks reach the rear side of the plate and the petalling failure mode is completed, Fig. 10d. Thus, plastic instabilities formation and progression is revealed as the mechanism behind target collapse in the impact tests. These observations are in agreement with the experimental evidences reported in [40-42].

For the whole range of impact velocities tested, the perforation mechanisms remain invariable. Petalling is the recurring failure mode for all the tests performed, using the drop weight tower setup, Figs. 11-13. It has been noticed that neither the rolling direction nor boundary conditions influence the initiation or the propagation of cracks.

Up to this point, no differences with the results observed by Rodríguez-Martínez et al. [18] for perforation of TRIP 1000 steel sheets are reported.

However in Fig. 14, different ballistic limit values depending on the material considered are illustrated. In the case of the AISI 304, the ballistic limit takes the value $V_{\text {bl-AISI }} 304=2.9 \mathrm{~m} / \mathrm{s}$, in the case of the TRIP $\mathbf{1 0 0 0}$ the ballistic limit takes the value $V_{\text {bl-TRIP } 1000}=2.6 \mathrm{~m} / \mathrm{s}$, Fig. 14 .

In fact, for the whole range of impact velocities tested, the AISI 304 absorbs quite larger amount of energy than the TRIP 1000, Fig. 15.

The causes behind the different impact behaviours of both materials can be derived from the recorded curves force/striker displacement, Fig. 16. a

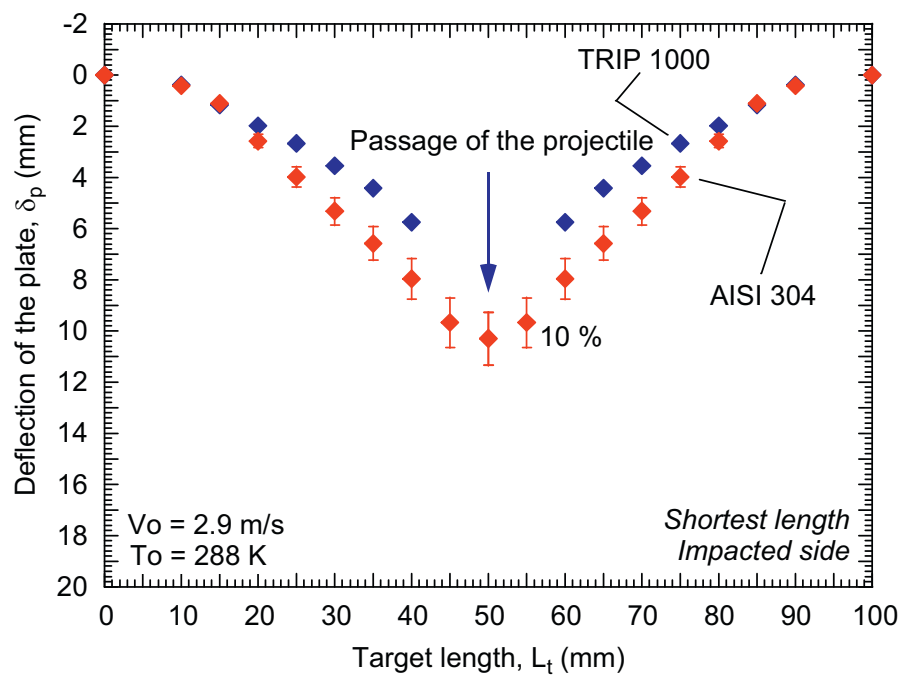

b

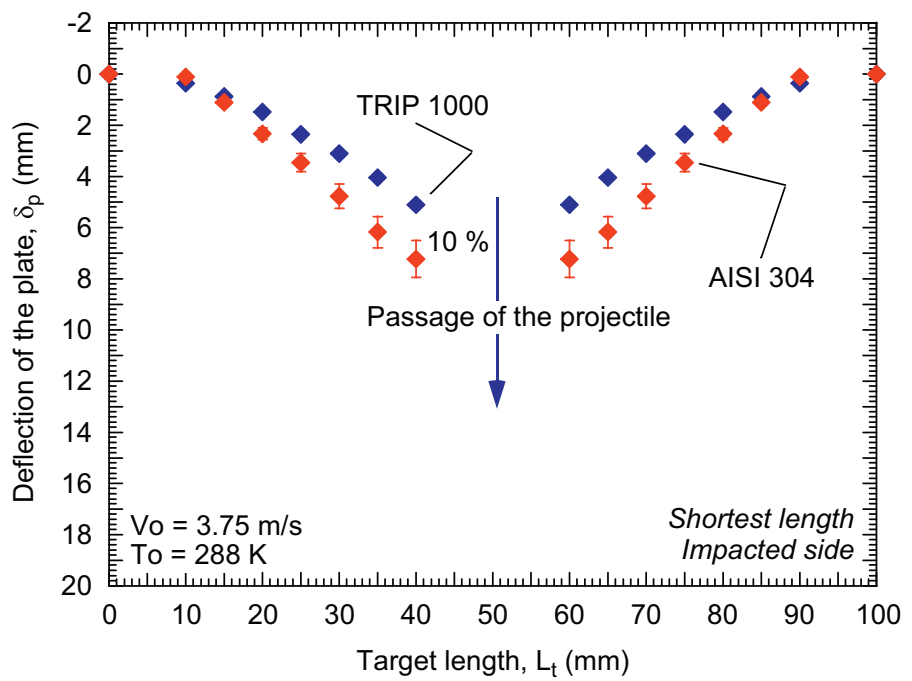

C

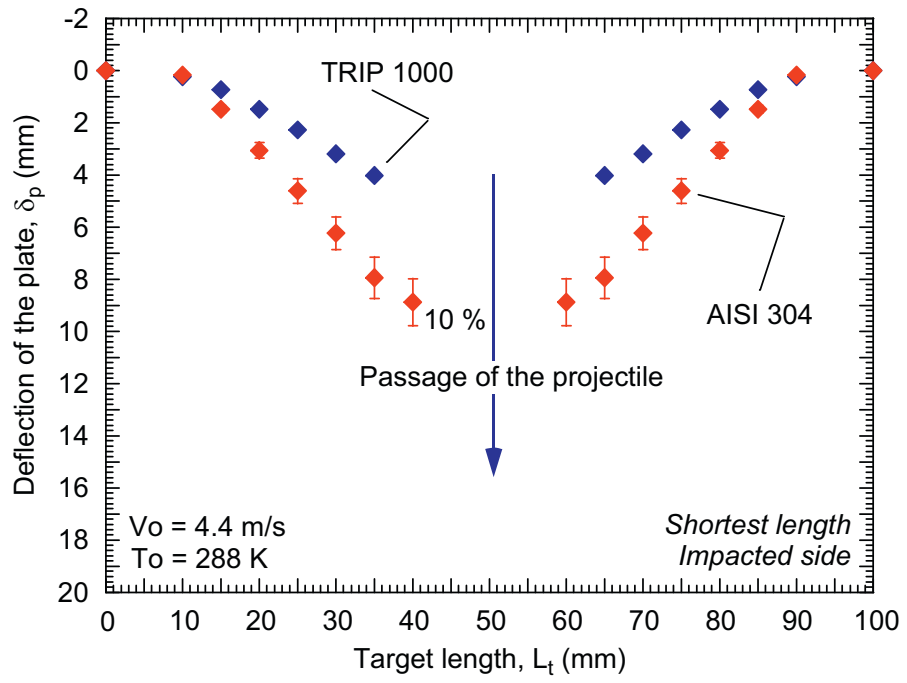

Fig. 17. Post-mortem deflection of the target for different impact velocities. Comparison between AISI 304 and TRIP 1000 steels. 
For all the impact velocities considered, in the case of the AISI 304 tests, the slope of curve force/striker displacement is lower than in the case of the TRIP 1000 tests, $\partial F /\left.\partial \delta_{s}\right|_{\text {AISI304 }}<$ $\partial F /\left.\partial \delta_{s}\right|_{\text {TRIP1000. However, the former material shows a larger }}$ striker displacement at failure, Fig. 16. The maximum force level during the tests remains approximately constant for both metals $\left.\left.F^{\mathrm{max}}\right|_{\text {AISI304 }} \approx F^{\mathrm{max}}\right|_{\text {TRIP1000 }} \approx 11 \mathrm{kN}$, Fig. 16 .

These observations may be explained as follows:

- In the case of the AISI 304 steel experiments, the lower slope of curve force/striker displacement is caused by the lower flow stress level of this material in comparison with the TRIP 1000 steel $\left.\sigma_{y}\right|_{\bar{\varepsilon}^{p}=0.02, \dot{\varepsilon}^{p}, T} ^{T R I P 1000} /\left.\sigma_{y}\right|_{\bar{\varepsilon}^{p}=0.02, \dot{\varepsilon}^{p}, T} ^{\text {AIS } 304} \approx 2$, Fig. 3 .

- The larger striker displacement at failure recorded in the case of the AISI 304 steel experiments is caused by its greater

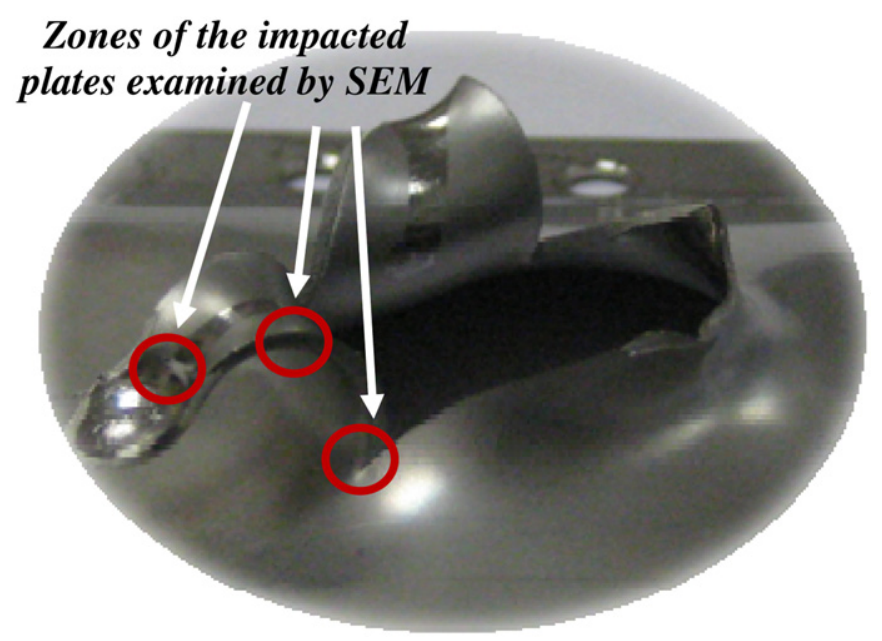

Fig. 18. Illustration of the zones of the impacted plates examined by an SEM. ductility in comparison with the TRIP $\mathbf{1 0 0 0}$ steel,

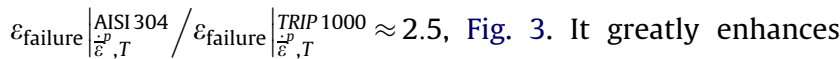
the absorption of energy by the AISI 304 plates, Fig. 15.

- Both materials show similar value for the maximum force recorded, since their flow stress level at failure is approximately coincident $\left.\sigma_{y}^{\max }\right|_{\substack{T R \\ \dot{\varepsilon}, T}} ^{T R I P 00} /\left.\sigma_{y}^{\max }\right|_{\substack{\vec{\varepsilon}, T \\ \vec{\varepsilon}, T}} ^{\text {AISI } 304} \approx 1$, Fig. 3.

Previous explanations match the observations derived from the analysis of the permanent deflection of the impacted samples, Fig. 17. Plastic work, under the form of bending, acts as the main mechanism for energy absorption during perforation. High work hardening exhibited by the AISI $\mathbf{3 0 4}$ spreads plasticity along the samples during perforation (high velocity of the plastic waves) increasing permanent bending of the target (permanent bending of the AISI 304 sheets is much greater than that of the TRIP 1000 sheets). It homogenizes material behaviour, delaying strain localization and leading to a global response to the impact by the whole plate, Fig. 17.

The next step is to determine, if martensitic transformation takes place in the AISI 304 sheets during perforation (a study by Rodríguez-Martínez et al. [18] reported the absence of martensite formation in the tested TRIP 1000 plates). As previously mentioned, martensitic transformation increases the hardening rate of steels delaying plastic instabilities formation. Therefore, the transformation process may be behind the good performance of the AISI 304 sheets under perforation.

For that task, the AISI 304 impacted plates have been cut; petals and cracking interfaces have been examined, using an SEM Fig. 18. For the whole range of impact velocities covered, martensite has been found in the tested specimens, Fig. 19. A relevant amount of grains partially transformed for different variants has been detected. In the zone directly affected by the impact, the complicated shape of the tested samples made nonviable the application of X-ray diffraction technique for
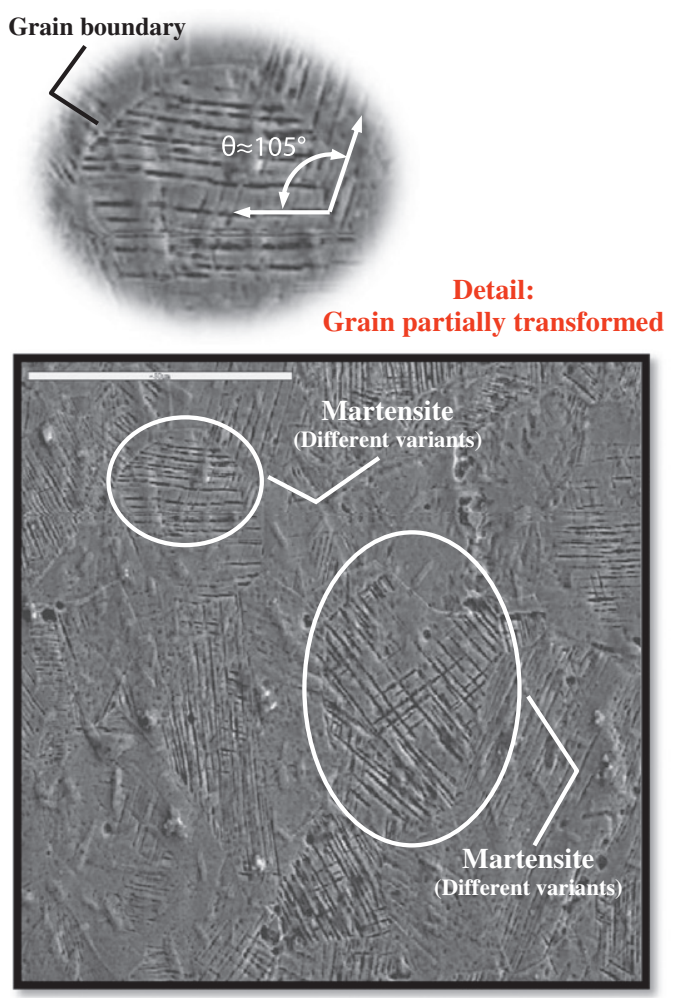

Detail:

Grain partially transformed

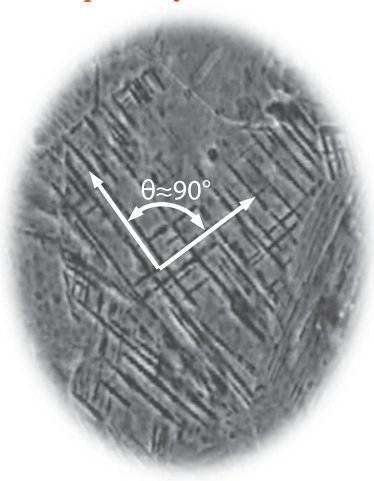

Fig. 19. SEM micrograph of the zone directly affected by the impact in AISI 304 tested plates, $V_{0}=4.4 \mathrm{~m} / \mathrm{s}$. 
determining the volume fraction of martensite. Unfortunately, the analysis conducted is merely qualitative.

The previous analysis leads to the conclusion that the AISI 304 steel can be an effective material for building protection structures in charge of absorbing energy under dynamic solicitations. Large hardening rate and elevated ductility, which are still remarkable under high loading rates, are the main responsible for such a behaviour.

Formation of martensite under dynamic solicitation seems to play a relevant role in the afore-mentioned considerations.

In order not to restrict previous findings to a particular boundary value problem, AISI $\mathbf{3 0 4}$ sheets are impacted, using a different experimental arrangement.

\subsection{The high velocity impact tests}

The results obtained for the AISI 304 sheets are compared with those reported by Rodríguez-Martínez et al. [21] for the perforation of ES steel sheets (both AISI 304 and ES steels samples are of the same size and thickness). Differences in the response of both materials under perforation are discussed.

Experiments within the range of impact velocities $25 \mathrm{~m} / \mathrm{s} \leq V_{0} \leq 85 \mathrm{~m} / \mathrm{s}$ are carried out using the pneumatic gas gun setup. The ballistic limit found from the tests is $V_{\mathrm{bl}-\mathrm{AISI}} 304$ $\approx 75 \mathrm{~m} / \mathrm{s}$. It is necessary to highlight that in comparison with ES steel, $V_{\mathrm{bl}-\mathrm{ES}} \approx 45 \mathrm{~m} / \mathrm{s}$ [21], AISI 304 steel shows a much greater ballistic limit value. Larger ductility and flow stress of the AISI $\mathbf{3 0 4}$ increase the ballistic limit value,

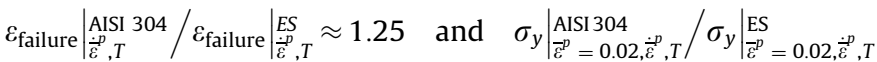
$\approx 2$, Fig. 3 .

It seems to be confirmed that the AISI 304 steel displays excellent mechanical properties for the absorption of energy under dynamic solicitations.

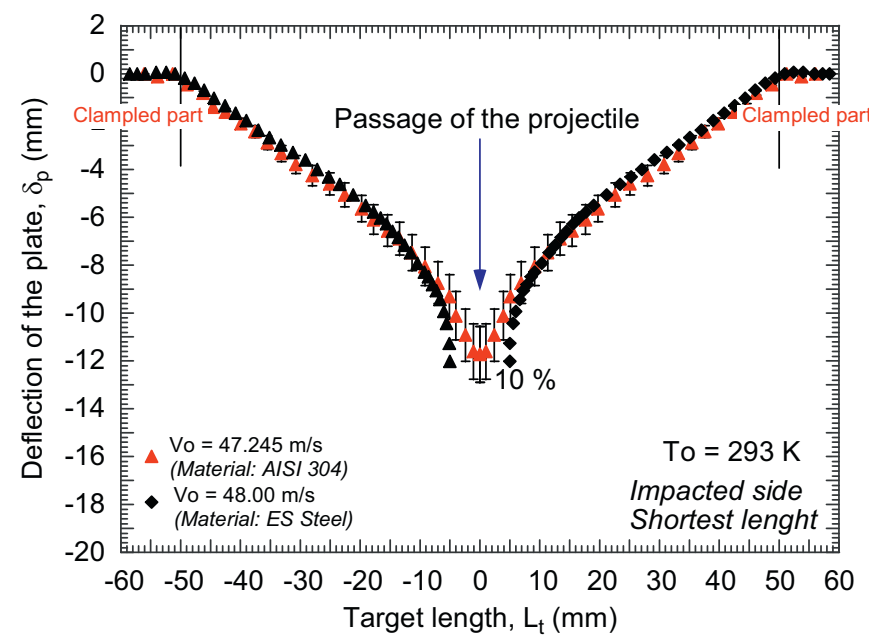

Fig. 21. Post-mortem deflection of the target for $V_{0} \approx 48 \mathrm{~m} / \mathrm{s}$ at room temperature. Comparison between AISI 304 and ES steels.

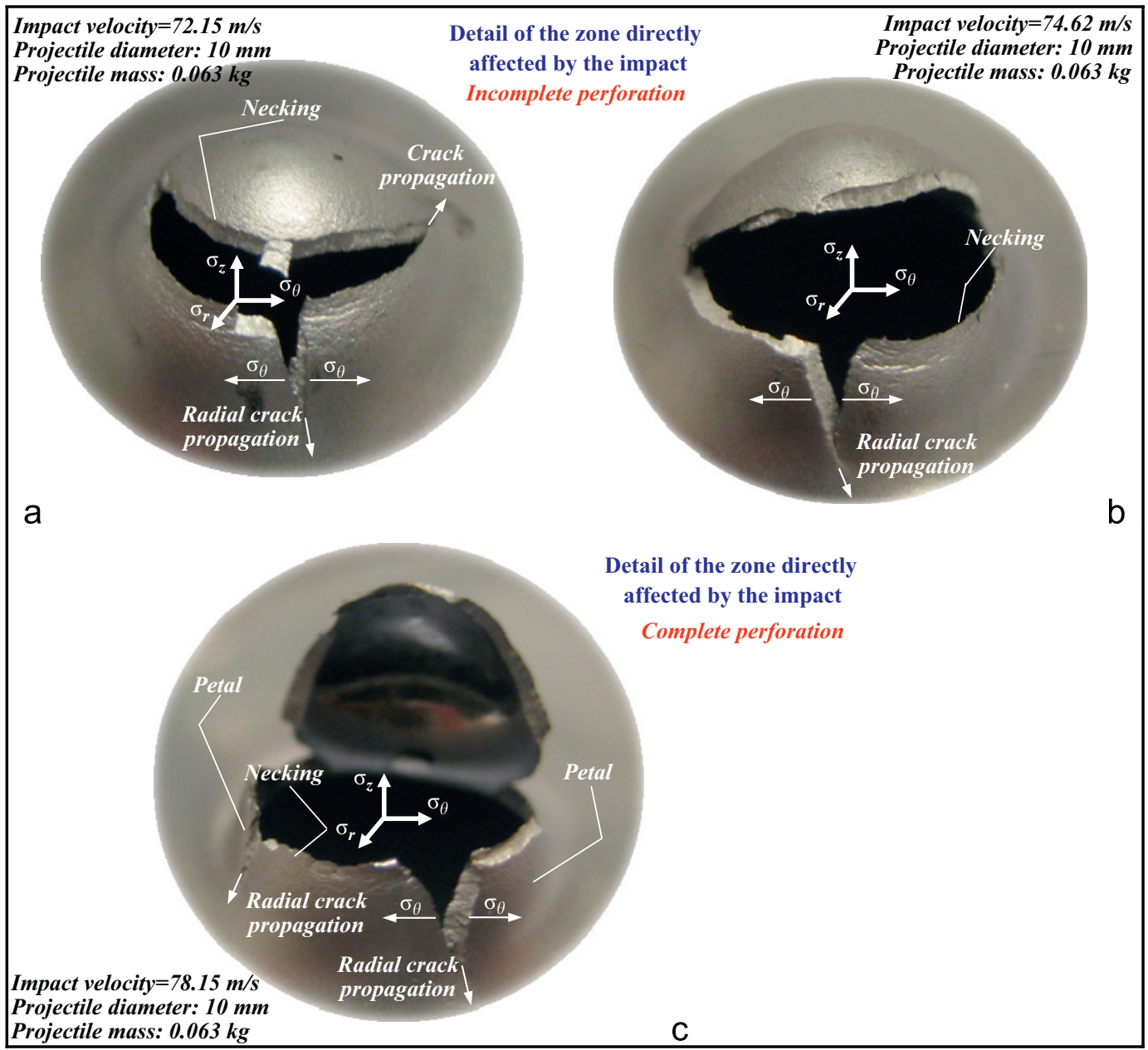

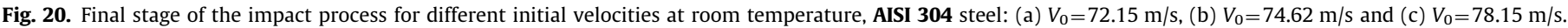


In Fig. 20. shows the final stage of the impact process for different initial impact velocities. Large bending of the steel sheets during perforation leads to considerable radial sliding projectile/plate. Necking formation and subsequent propagation of cracks is the recurrent failure mode of the plates. Necking takes place close to the dome of the contact projectile/plate and petals are formed as the final stage of the perforation process, Fig. 20.

Next, permanent deflection of impacted AISI 304 samples is compared with that of impacted ES steel specimens, Fig. 21. For a given initial velocity, $V_{0} \approx 48 \mathrm{~m} / \mathrm{s}$, the AISI 304 and the ES steel sheets show quite similar permanent deflections. In the case of ES steel such a loading condition corresponds to maximum bending ( $\approx$ ballistic limit). However, in the case of AISI 304 bending is even more increased until the ballistic limit velocity is reached, Fig. 22.

As mentioned previously for the drop weight tower tests, plastic work under the form of bending, acts as the main mechanism responsible for energy absorption during perforation.

In order to understand the good performance of the AISI 304 sheets in the gas gun tests, the procedure followed for analyzing the martensite transformation in the drop weight tower tests has a

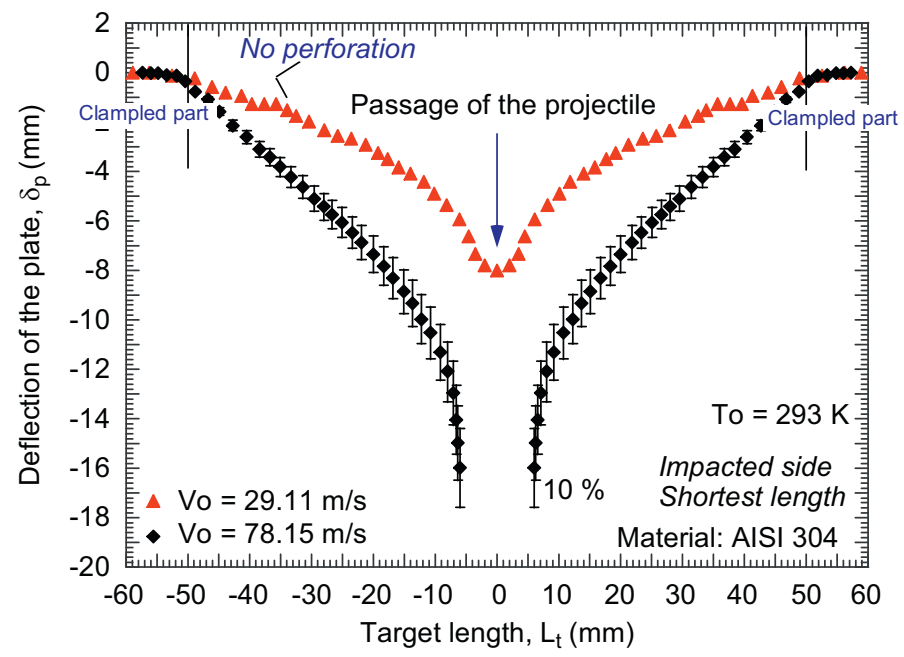

b

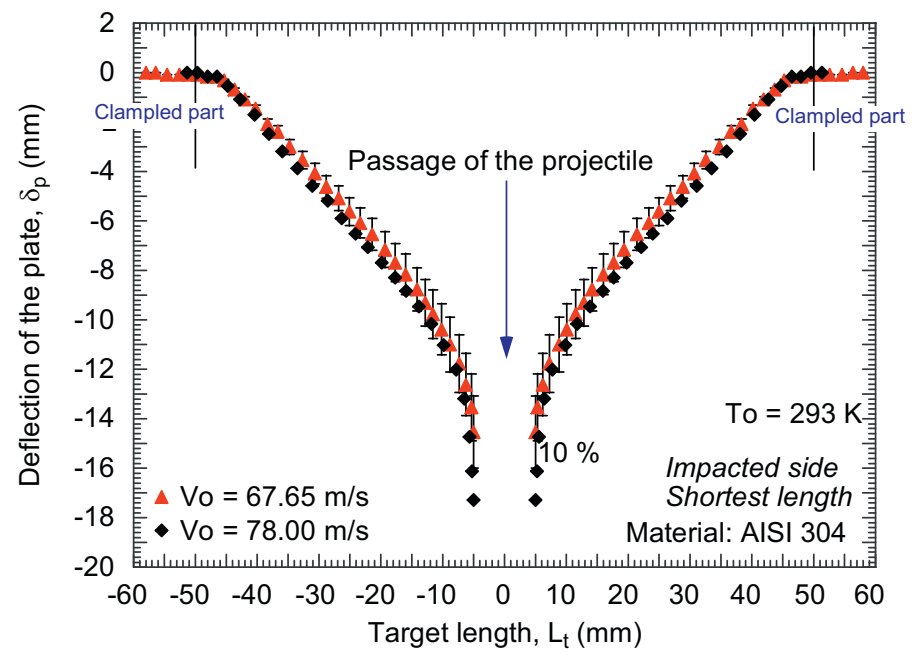

Fig. 22. Post-mortem deflection of the target for different initial impact velocities at room temperature, AISI 304 steel.
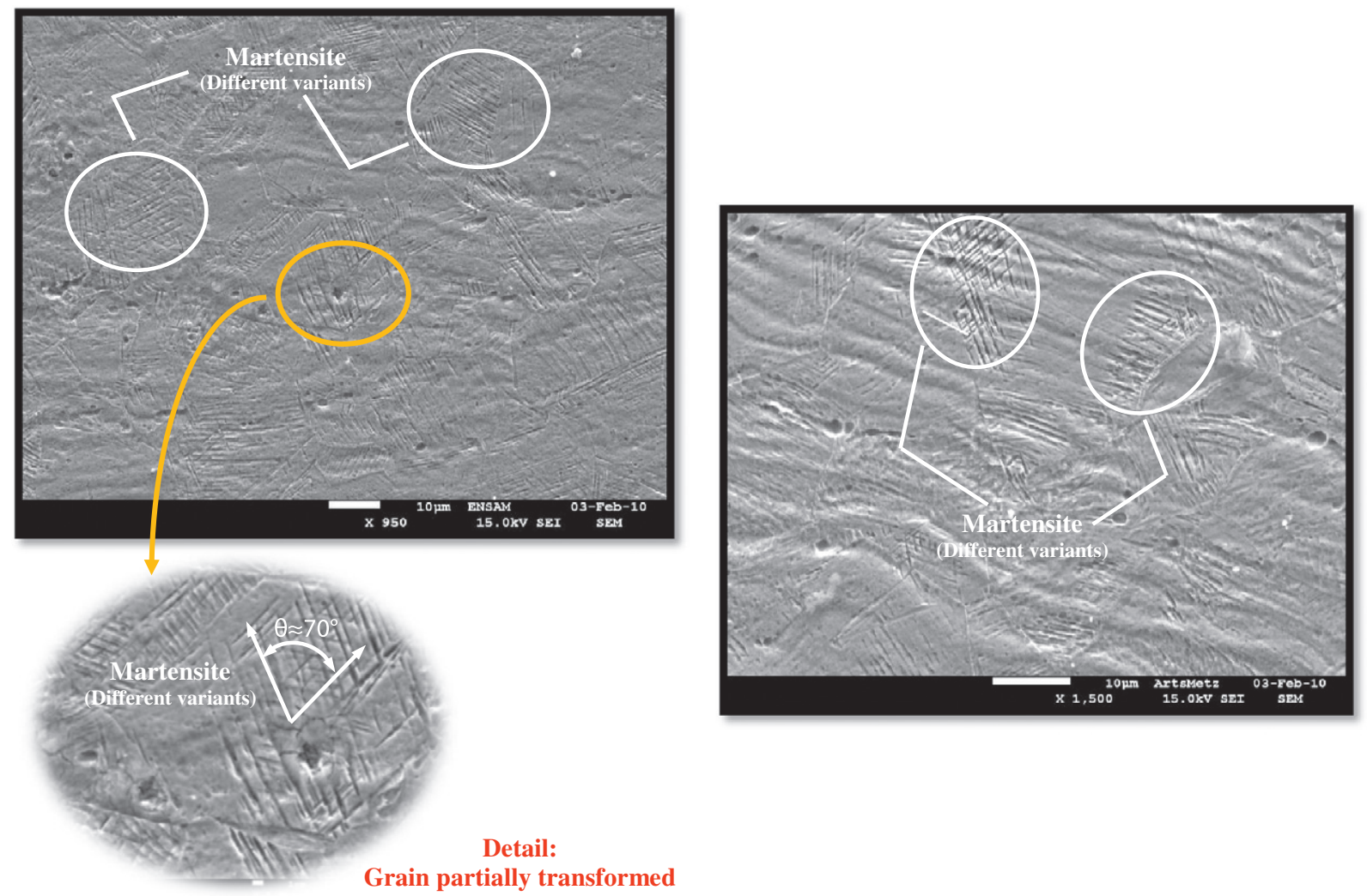

Fig. 23. SEM micrographies of the zone directly affected by the impact in a tested plate for $V_{0}=78.15 \mathrm{~m} / \mathrm{s}$ at room temperature, AISI 304 steel. 
been repeated. Again, martensite has been found for the whole range of impact velocities considered, particularly in the petals and around the cracks (strong material deformation makes the observation of the microstructure difficult; however, traces of martensite are visible in all cases), Fig. 23.

Thus, from previous analysis it has been proven that in the AISI

304 steel martensite is formed by material straining even under high velocity impact events. It makes this material suitable for bearing dynamic solicitations.

In forthcoming investigations, it is necessary to determine accurately which variants are activated in the martensitic transformation, Figs. 19 and 23, and the causes behind such preferential activation (crystallographic orientation of grains, loading path). In addition, it would be interesting to identify precisely the strain rate and temperature levels under which austenite transforms into martensite during perforation of AISI 304 sheets. For that task, advanced measuring techniques like infrared recording and picture image correlation may be applied.

Moreover, other engineering metals and alloys like two-phase and multiphase steels susceptible of martensitic transformation under high loading rates should be examined.

\section{Conclusion and remarks}

In this work, the behaviour of AISI 304 steel sheets subjected to perforation under wide ranges of impact velocities $2.5 \mathrm{~m} / \mathrm{s} \leq V_{0} \leq 85 \mathrm{~m} / \mathrm{s}$ has been examined. For that task, two different experimental arrangements have been used, a drop weight tower and a pneumatic gas gun. The results from these perforation tests are compared with those previously published by the authors in [18,21] for mild steel ES and TRIP 1000 steel. The comparison reveals the good performance of the AISI 304 under high loading rates. The high work hardening and ductility exhibited by this steel under dynamic solicitations are identified as responsible for such behaviour. It has been proven that those characteristics are enhanced by the martensitic transformation taking place in this material during perforation. The transformation delays flow localization improving the capability of the AISI $\mathbf{3 0 4}$ for absorbing energy under impact events.

\section{Acknowledgements}

The authors express their thanks to Dr. Edgar Dossou from LPMM, to Mr. J. Puerta and to Mr. S. Puerta from UC3M and to Ms. D. Kreicher and Mr. P. Schmitt from ENIM for their technical support.

The researcher of the University Carlos III of Madrid is indebted to the Comunidad Autónoma de Madrid (Project CCG08-UC3M/MAT-4464) and to the Ministerio de Ciencia e Innovación de España (Project DPI/2008-06408) for the financial support received which allowed conducting part of this work.

\section{References}

[1] Molinari AC, Musquar CG, Sutter G. Adiabatic shear banding in high speed machining of Ti-6Al-4V: experiments and modeling. Int J Plasticity 2002;18:443-59.

[2] Børvik T, Hopperstad OS, Berstad T. On the influence of stress triaxiality and strain rate on the behaviour of a structural steel. Part II. Numerical study. Eur J Mech A/Solids 2003;22:15-32.

[3] Arias A, Rodríguez-Martínez JA, Rusinek A. Numerical simulations of impact behaviour of thin steel to cylindrical, conical and hemispherical nondeformable projectiles. Eng Fract Mech 2008;75:1635-56.

[4] Rusinek A, Rodríguez-Martínez JA, Arias A, Klepaczko JR, López-Puente J. Influence of conical projectile diameter on perpendicular impact of thin steel plate. Eng Fract Mech 2008;75:2946-67.
[5] Klepaczko JR, Rusinek A, Rodríguez-Martínez JA, Pecherski RB, Arias A. Modeling of thermo-viscoplastic behaviour of DH-36 and Weldox 460-E structural steels at wide ranges of strain rates and temperatures, comparison of constitutive relations for impact problems. Mech Mater 2009;41:599-621.

[6] Abramowicz W, Jones N. Dynamic axial crushing of square tubes. Int J Impact Eng 1984;2:179-208.

[7] Abramowicz W, Jones N. Dynamic axial crushing of circular tubes. Int J Impact Eng 1984;2:263-81.

[8] Rusinek A, Zaera R, Forquin P, Klepaczko JR. Effect of plastic deformation and boundary conditions combined with elastic wave propagation on the collapse site of a crash box. Thin-Walled Struct 2008;46:1143-63.

[9] Fischer FD, Oberaigner ER, Tanaka K, Nishimura F. Transformation induced plasticity revised an updated formulation. Int J Solids Struct 1998;35: 2209-27.

[10] Levitas VI. Thermomechanical theory of martensitic phase transformations in inelastic materials. Int J Solids Struct 1998;35:889-940.

[11] Huh H, Kim SB, Song JH, Lim JH. Dynamic tensile characteristics of TRIP-type and DP-type steel sheets for an auto-body. Int J Mech Sci 2008;50:918-31.

[12] Fischer FD, Reisner G, Werner E, Tanaka K, Cailletaud G, Antretter T. A new view on transformation induced plasticity (TRIP). Int J Plasticity 2000;16: 723-748.

[13] Delannay L, Jacques P, Pardoen T. Modelling of the plastic flow of trip-aided multiphase steel based on an incremental mean-field approach. Int J Solids Struct 2008;45:1825-43.

[14] Angel T. Formation of martensite in austenitic stainless steels. Effects of deformation, temperature and composition. J Iron Steel Inst 1954;177: 165-74.

[15] Olson GB, Cohen M. Kinematics of strain-induced martensitic nucleation. Metall Trans A 1975;6:791-5.

[16] Curtze S, Kuokkala VT, Hokka M, Peura P. Deformation behavior of TRIP and DP steels in tension at different temperatures over a wide range of strain rates. Mater Sci Eng A 2009;507:124-31.

[17] Lebedev A, Kosarchuk V. Influence of phase transformations on the mechanical properties of austenitic stainless steels. Int J Plasticity 2000;16: 749-767.

[18] Rodríguez-Martínez JA, Pesci R, Rusinek A, Arias A, Zaera R, Pedroche DA. Thermo-mechanical behaviour of TRIP 1000 steel sheets subjected to low velocity perforation by conical projectiles at different temperatures. Int J Solids Struct 2010;47:1268-84.

[19] Tomita Y, Iwamoto T. Constitutive modelling of TRIP steel and its application to the improvement of mechanical properties. Int J Mech Sci 1995;37: 1295-305.

[20] Tomita Y, Iwamoto T. Computational prediction of deformation behavior of TRIP steels under cyclic loading. Int J Mech Sci 2001;43:2017-34.

[21] Rodríguez-Martínez JA, Rusinek A, Chevrier P, Bernier R, Arias A. Temperature measurements on ES steel sheets subjected to perforation by hemispherical projectiles. Int J Impact Eng 2010;37:828-41.

[22] De AK, Speer JG, Matlock DK, Murdock DC, Mataya MC, Comstock RJ Deformation-induced phase transformation and strain hardening in type 304 austenitic stainless steel. Metall Mater Trans A 2006;37:1875-86.

[23] Hecker SS, Stout MG, Staudhammer KP, Smith JL. Effects of strain and strain rate on deformation-induced transformation in 304 stainless steel: Part I. Magnetic measurements and mechanical behaviour. Met Trans A 1982;13A: 619-626.

[24] Magee, CL Transformation kinetics, micro-plasticity and aging of martensite in Fe-31 Ni. 1966; PhD Thesis, Carnegie Inst Tech, Pittsburgh, PA.

[25] Leblond JB, Devaux J, Devaux JC. Mathematical modelling of transformation induced plasticity in steels-I. Case of ideal-plastic phases; II. coupling with strain hardening phenomena. Int J Plasticity 1989;5:551-73.

[26] Rodríguez-Martínez JA. Advanced constitutive relations for modeling thermoviscoplastic behaviour of metallic alloys subjected to impact loading. PhD Thesis. University Carlos III of Madrid-University Paul Verlaine of Metz/ENIM 2010.

[27] Zhao H, Gary G. The testing and behaviour modelling of sheet metals at strain rates from $10^{-4}$ to $104 \mathrm{~s}^{-1}$. Mater Sci Eng 1996;207:46-50.

[28] Klepaczko JR, Viem Nguyen H, Nowacki WK. Quasi-static and dynamic shearing of sheet metals. Eur J Mech 1999;18:271-89.

[29] Mouro P, Gary G, Zhao H. Dynamic tensile testing of sheet metal. J Phys IV 2000;10:149-54.

[30] Rusinek A, Klepaczko JR. Shear testing of sheet steel at wide range of strain rates and a constitutive relation with strain-rate and temperature dependence of the flow stress. Int J Plasticity 2001;17:87-115.

[31] Haugou G, Markiewicz E, Fabis J. On use of the non-direct tensile loading on a classical split Hopkinson bar apparatus dedicated to sheet metal specimen characterisation. Int J Impact Eng 2006;32:778-98.

[32] Rusinek A, Klepaczko JR. Experiments on heat generated during plastic deformation and stored energy for TRIP steels. Mater Des 2009;30:35-48.

[33] Durrenberger L, Even D, Molinari A, Rusinek A. Influence of the strain path on crash properties of a crash-box structure by experimental and numerical approaches. J Phys IV 2006;134:1287-93.

[34] Rusinek A, Zaera R, Klepaczko JR. Constitutive relations in 3-D for a wide range of strain rates and temperatures-application to mild steels. Int J Solids Struct 2007;44:5611-34

[35] Follansbee PS. High-strain-rate deformation of FCC metals and alloys. Metall Appl Shock-Wave High-Strain-Rate Phenom 1986:451-79.

[36] Campbell JD, Ferguson WG. The temperature and strain-rate dependence of the shear strength of mild steel. Philos Mag 1970;81:63-82. 
[37] Nemat-Nasser S, Guo WG, Kihl DP. Thermomechanical response of AL-6XN stainless steel over a wide range of strain rates and temperatures. J Mech Phys Solids 2001;49:1823-46.

[38] Rusinek A, Rodríguez-Martínez JA. Thermo-viscoplastic constitutive relation for aluminium alloys, modeling of negative strain rate sensitivity and viscous drag effects. Mater Des 2009;30:4377-90.

[39] Kapoor R, Nemat-Nasser S. Comparison between high strain-rate and low strain-rate deformation of tantalum. Metall Mater Trans 1999;31A:815-23.
[40] Landkof B, Goldsmith W. Petalling of thin, metallic plates during penetration by cylindro-conical projectiles. Int J Solids Struct 1993;21:245-66.

[41] Wierzbicki T. Petalling of plates under explosive and impact loading. Int J Impact Eng 1999;22:935-54.

[42] Rusinek A, Rodríguez-Martínez JA, Zaera R, Klepaczko JR, Arias A, Sauvelet C. Experimental and numerical analysis of failure process of mild steel sheets subjected to perpendicular impact by hemispherical projectiles. Int J Impact Eng 2009;36:565-87. 